\title{
Aquatic exercise and cardiac autonomic modulation of postmenopausal women with type 2 diabetes
}

\section{Aquatic exercise and cardiac autonomic modulation of postmenopausal women with type 2 diabetes}

\author{
Eduardo Federighi Baisi Chagas ${ }^{1,2}$, Angélica Cristiane da Cruz², Pedro Henrique \\ Rodrigues ${ }^{2}$, Cristiano Sales da Silva ${ }^{2,3}$, Robison José Quitério ${ }^{2}$ \\ 1. Universidade de Marilia (UNIMAR), Marília/SP, Brazil. \\ 2. Programa de post-graduação em desenvolvimento humano e tecnologia, Insituto de Biociências (UNESP), Campus Rio \\ Claro, Rio Claro/SP, Brazil. \\ 3. Universidade Federal do Piauí (UFPI), Departamento de Fisioterapia, Campus de Parnaíba/PI, Brazil.
}

\begin{abstract}
Objective: Investigating the effect of 12 weeks of an aquatic exercise program on cardiac autonomic modulation by heart rate variability index of postmenopausal women with type 2 diabetes mellitus (T2DM). Methods: A randomized clinical trial was performed in 25 women aged 51 to 83 years, divided into exercise group $(E G)(n=13)$ submitted for 12 weeks to two weekly sessions of 50 minutes each, and control group (CG) (n $=12$ ) without exercise. Results: Regarding cardiac autonomic modulation significant interaction was observed for TINN values (ms), indicating a slight increase in EG, but mostly a reduction in CG. The regression analysis also pointed effect of aquatic exercise on reducing the LF/HF ratio, after controlling for covariates diastolic blood pressure and dyslipidemia. Conclusion: The aquatic exercise had a significant effect on the reduction of cardiovascular risk, mainly in relation to glycemia and abdominal obesity, which may represent a protective effect of exercise in the progression of autonomic dysfunction, but its effect on autonomic modulation seems to depend on a greater volume and time with aquatic exercise.
\end{abstract}

Key-words: diabetes, women, menopause, autonomic nervous system.

\section{RESUMO}

Objetivo: Investigar o efeito de 12 semanas de um programa de exercícios aquáticos na modulação autonômica cardíaca pelo índice de variabilidade da frequência cardíaca (VFC) de mulheres com diabetes mellitus tipo 2 (DM2) na pós-menopausa. Métodos: Um ensaio clínico randomizado foi realizado em 25 mulheres com idade entre 51 e 83 anos, dividido em grupo de exercício $(\mathrm{GE})(\mathrm{n}=13)$, submetido por 12 semanas a duas sessões semanais de 50 minutos cada, e grupo controle $(\mathrm{GC})(\mathrm{n}=12)$ sem exercício. Resultados: Em relação à modulação autonômica cardíaca, foi observada interação significativa para os valores de TINN (ms) indicando um pequeno aumento no GE, mas principalmente uma redução no GC. A análise de regressão também apontou o efeito do exercício aquático na redução da razão LF/HF, após o controle de covariáveis pressão arterial diastólica e dislipidemia. Conclusão: $\mathrm{O}$ exercício aquático teve um efeito significativo na redução do risco cardiovascular, principalmente em relação à glicemia e obesidade abdominal, o que pode representar um efeito protetor do exercício na pro- 
gressão da disfunção autonômica, mas seu efeito na modulação autonômica parece depender de maior volume e tempo com exercícios aquáticos.

Palavras-chave: diabetes, mulheres, menopausa, sistema nervoso autonômico.

\section{Introduction}

The complications in type 2 diabetes mellitus (T2DM) are partly due to the hyperglycemic state to active toxic pathways in the independent insulin tissues causing cell damage, which in turn raises the cardiovascular risk [1]. In women the changes of sex steroid hormones in the postmenopausal period is associated with an increased risk of cardiovascular disease, and also affect the heart rate and the regulation of the autonomic nervous system (ANS) [2].

In endothelial cells, hyperglycemia alters nerve blood flow decreasing nerve buffering capacity free radicals, and the depleting energy reserves available resulting in cellular necrosis and activation of genes involved in neuronal damage [3]. Thus chronic hyperglycemia is involved in the destruction process and the myelin sheath of nerve fibers, resulting in autonomic dysfunction and decreased heart rate variability (HRV) observed in neuropathies [4].

The ANS is an important component of the homeostasis control, and the reduction in capacity has been related to various diseases of the cardiovascular system [5]. In the case of T2DM, the damage to the ANS is directly related to the duration of the disease, and therefore, clinical applications of tools that allow review are of fundamental importance [6]. The analysis of HRV is one of these methods, and allows monitoring of disease progression and therapeutic efficacy of interventions [7].

As for the treatment strategies in type 2 diabetes, exercise is widely recommended by contributing to a better glycemic control and reduces cardiovascular risk factors $[8,9]$. However the study of the therapeutic effect of exercise on cardiac autonomic modulation is still recent, and although there is evidence that aerobic and resistance exercise have a positive effect on the autonomic modulation in high-risk populations [10] there are also studies that found no significant improvement after combined aerobic and resistance training exercise $[11,12]$.

In addition, when considering aquatic exercise, there is little evidence about the effect of this type of exercise in improving cardiac autonomic modulation $[13,14]$ mainly in the population of post-menopausal women with type 2 diabetes. Thus, the purpose of the study was to analyze the effect of an aquatic exercise program on cardiac autonomic modulation by analysis of heart rate variability in women with postmenopausal type 2 diabetes mellitus.

\section{Methods}

\section{Population of study and casuistic}

The sample size ( $\mathrm{n}$ ) was determined to analyze the interaction between group and intervention time by ANOVA repeated measures between groups. The sample was considered to calculate an average effect size (0.30), a margin 
of error type I $(\alpha)$ of $5 \%$ and $80 \%$ power study indicating the need for sample 24 sample elements. The calculation of the size of the sample was held at $G^{*}$ Power software, version 3.1.9.2 (Franz Faul, University of Kiel, Germany). The sample consisted of 26 women aged 51-83 years with amenorrhea for at least 12 months, diagnosed with type 2 diabetes for at least three years and sedentary $(<150$ minutes per week of moderate or vigorous exercise in the last three months).

An intervention study was performed (treatment), parallel of two arms, open-masking and randomized controlled allocation. Figure 1 shows the following flow chart of the study participants. Patients were submitted to an initial evaluation with history of the disease, drug therapy, postmenopausal status and physical activity patterns. After the initial evaluation, the volunteers included in the study underwent anthropometric averages, fasting blood glucose, blood pressure and registration of RR intervals (RR intervals) for analysis of heart rate variability (HRV). Later the volunteers were randomized and allocated to exercise group (EG) and control group (CG). The allocation was made through drawing in a sealed envelope. Data collection was performed on two non-consecutive days and repeated after 12 weeks of the intervention period. The post-intervention measurements were performed seven days after the end of the intervention period. After the end of the study the patients allocated to the $C G$ were invited to participate in aquatic exercise program on the same terms available to GE.

They were initially included in the study all patients with T2DM and medical referral to Physical Evaluation Laboratory and Practice of Sports Unimar (LAFIPE-UNIMAR) to practice aquatic exercise. Patients were not included in the study: they were unable to enter and exit independently of the pool; inability to understand and follow simple verbal command; amputations and / or use of prosthetic limbs; stroke sequelae; Parkinson's disease; fractures of the lower limbs and / or column after 60 years; disabling labyrinth; otitis; hydrophobia; skin lesions; unstable angina; hypertension uncontrolled and foot deformity. Patients who did not complete the evaluation protocol and intervention were excluded of the study.

The project was approved by the Ethics Committee of the University of Marilia-SP (UNIMAR) ( ${ }^{\circ}{ }^{\circ} 1441220 / 2016$ protocol CAAE: 53040116.2.0000.5496), and followed the criteria established by resolution of the National Health Council (CNS 466 / 12). The test was recorded in Rebec (Brazilian Registry of Clinical Trials) (Registry Number: RBR-8btc25).

The 12 selected articles were evaluated on the PEDro scale according to the following quality indicators of the evidence presented: 1. specification of the inclusion criteria (item not scored); 2. random allocation; 3. secrecy in the allocation; 4 . Similarity of the groups in the initial or baseline phase; 5 . masking the subjects; 6 . masking those responsible for the intervention; 7 . masking the evaluator; 8 . measurement of at least one primary outcome in $85 \%$ of the allocated subjects; 9. analysis of the intention to treat; 10 . comparison between groups of at least one primary outcome; and 11. reporting of variability measures and estimating parameters for at least one primary variable, who received an assigned point (in relation to presence) or no assigned point (in relation to absence) of the indicators. The articles selected in this study are shown in Table I. 


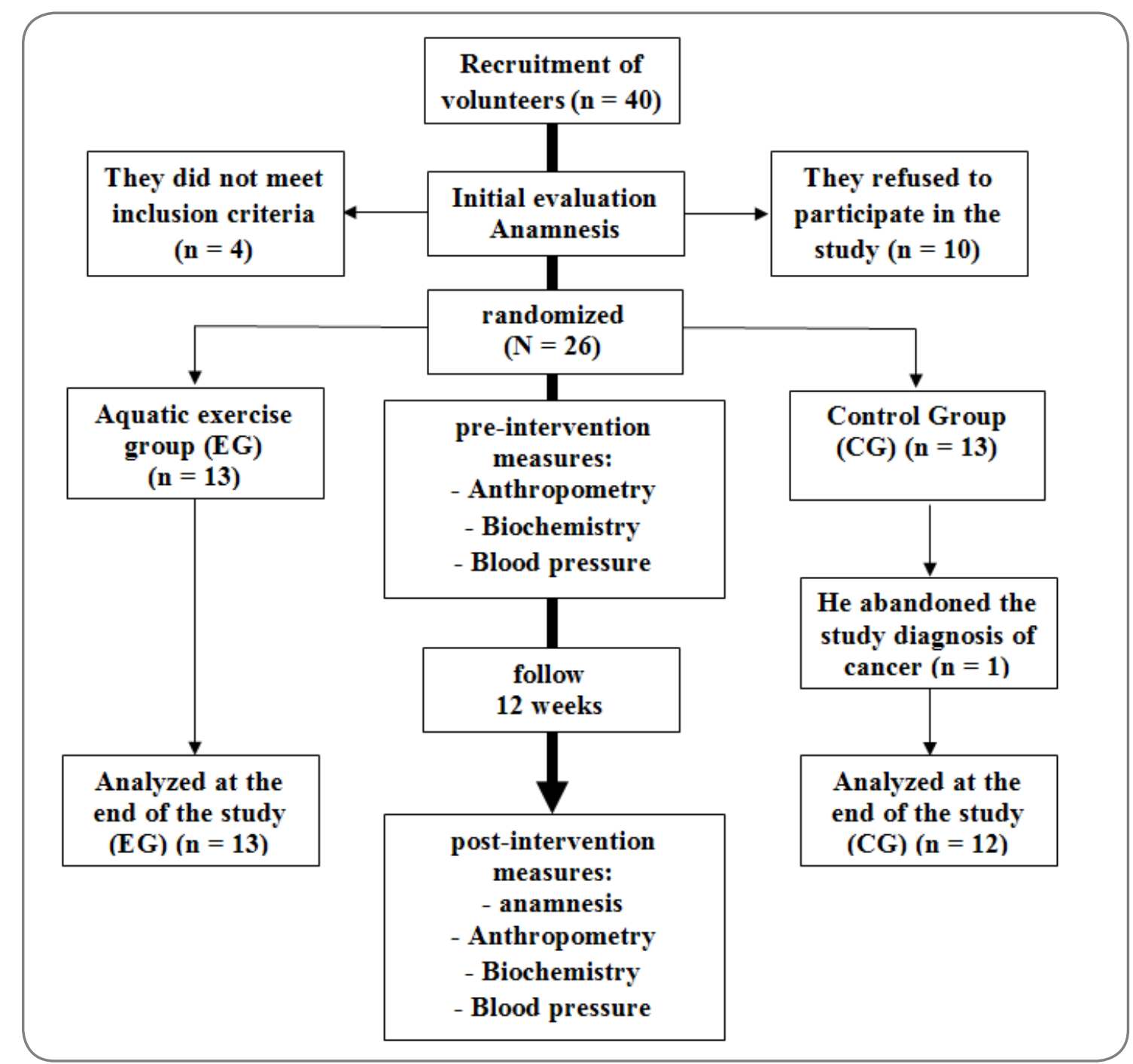

Figure 1 - Flow chart tracking of volunteers.

\section{Study variables}

The prevalence of chronic diseases in the study population was obtained by questionnaire of referred morbidities, and confirmed by clinical diagnosis in the medical this routing. The reported morbidity questionnaire contains information about the presence or absence of chronic diseases distributed in metabolic, cardiovascular and rheumatology, as well as the time of diagnosis of the disease and information on the use of medicines. The questionnaire was supplemented with information on the pattern of habitual physical activity in the last three months.

\section{Cardiovascular risk factors}

The fasting blood glucose (FBG) were performed on biochemical analyzer spectrophotometric reflectance (Accutrend Plus, Roche Diagnostics, 2007) in venous blood by cubital puncture after overnight fasting 8 hours. Blood pressure (BP) was measured in supine position after twenty minutes of rest with automatic digital equipment (Omron HEM-742-INT China).

For the analysis of body composition were taken anthropometric measurements of weight, height and waist circumference (WC). WC values $\geq 80 \mathrm{~cm}$ 
were classified as central obesity. The values of the Body Mass Index (BMI) $\geq 30$ were classified as general obesity [15].

\section{Heart rate variability}

Heart rate (HR) and the instantaneous RR intervals were recorded for 20 minutes in the supine position for a digital telemetry system (Polar RS800CX, Polar Electro Oy, Kempele, Finland). Stable stretches were selected from 256 points series, and later analyzed in Kubios Software (HRV version 2.0, University of Kuopio, Finland). In the time domain the following calculations were made statistical the square root of the average squared differences between successive regular intervals (RMSSD), expressed in ms; and base width histogram of the RR interval (TINN). For the analysis in the frequency domain was used the autoregressive method considering the signal in the bands high-frequency (HF -0.15 to $0.4 \mathrm{~Hz}$ ) and low frequency (LF - 0.04 and $0.15 \mathrm{~Hz}$ ) for calculating the LF / HF ratio represents the sympatho-vagal balance. We also calculated the SD1 and SD2 derivatives of Poincaré plot [16].

\section{Intervention procedures}

The intervention period was 12 weeks with two weekly sessions lasting 50 minutes each for the exercise group (EG). The control group (CG) received guidelines for the maintenance of living habits and physical activity identified in the baseline. The training sessions were held in heated at medium temperature of $28^{\circ} \mathrm{C}, 1.3 \mathrm{~m}$ deep and in groups of up to six volunteers.

In the initial phase ( 5 minutes) were performed active stretching exercises lasting 30 seconds each and dynamic exercises in sets of 10 repetitions for the joints, neck, shoulders, elbows, wrists, hips, knee and ankle. In the main phase (40 minutes) were carried out six pack exercises with 5 minutes each, combining movements of the upper limbs (MMS) and lower limbs (MMI), totaling 30 minutes [17]. The target intensity was moderate to vigorous, controlled by the scale of perceived exertion between 12 to 14 points according to Borg's scale ( 6 to 20) [18]. The final phase lasted 5 minutes, where stretching exercises were performed like the initial phase (deltoids, biceps, triceps, pectorals, dorsal, quadriceps, hamstrings and calf).

\section{Statistical analysis}

Quantitative variables are described as mean and standard deviation (SD). The qualitative variables are described by the distribution of the absolute frequency ( $\mathrm{f}$ ) and relative (\%). To analyze the association between qualitative variables was used the Fisher's exact test. The distribution normality was verified by the Shapiro-Wilk test with Lilliefors correction. To analyze the effect of intervention between the groups (control vs. exercise) a mixed ANOVA was built for repeated measures, followed by Bonferroni post-hoc test to analyze the effect within groups. The effect size was determined by means of the square values ETA $(\eta 2)$. The delta change $(\Delta)(\Delta=$ Post training - Pre training) between the pre and post-intervention was used to quantify the variation of quantitative variables. Multiple linear regression was used to analyze the effect of the 
group, as well as the values at baseline and covariates on the delta change in the HRV index. The R2 was analyzed to check the determination of the percentage coefficient of variation explained by the model. For all analyzes, we used the SPSS software version 19.0 for windows, adopting a significance level of $5 \%$.

\section{Results}

The average adherence of the exercise group in aquatic exercise sessions was $65 \%$ for a total of 24 sessions. It was not observed significant differences between the groups for age, time since diagnosis of T2DM, morbidities and medication therapy at baseline (Table I). Regarding the use of beta-blockers (atenolol and propranolol) dosing was observed between 20 to $50 \mathrm{~m} /$ day. A significant reduction in fasting blood glucose, $\mathrm{BMI}$ and $\mathrm{CC}$ was observed in the exercise group, but no significant change in systolic (SBP) and diastolic (DBP) pressure. In the control group there was no significant change in body composition and blood pressure, with the exception of fasting glucose values and waist circumference showed a significant increase (Table II).

Table I - Mean and standard deviation (SD) of age and time of diagnosis and intervention of the control group.

\begin{tabular}{|c|c|c|c|}
\hline & Control $(n=12)$ & Exercise $(n=13)$ & \\
\hline & Mean $¥$ SD (\%) & Mean $¥ \mathrm{SD}(\%)$ & p-value \\
\hline Age (years) & $65.6 \pm 10.1$ & $66.6 \pm 6.7$ & 0.764 \\
\hline $\begin{array}{l}\text { Time Diagnostic DM2 } \\
\text { (years) }\end{array}$ & $12.6 \pm 9.1$ & $8.2 \pm 4.7$ & 0.134 \\
\hline \multicolumn{4}{|l|}{ Morbidities } \\
\hline Hypertension & 100.0 & 76.9 & 0.220 \\
\hline Abdominal obesity (WC) & 75.0 & 92.3 & 0.322 \\
\hline Global obesity (BMI) & 41.7 & 69.2 & 0.174 \\
\hline Osteoarthritis & 66.7 & 46.2 & 0.593 \\
\hline Dyslipidemia & 50.0 & 46.2 & 0.851 \\
\hline Osteoporosis & 25.0 & 15.0 & 0.645 \\
\hline Arthritis & 8.3 & 23.1 & 0.428 \\
\hline \multicolumn{4}{|l|}{ Medication } \\
\hline Beta-blocker & 33.3 & 38.5 & 0.794 \\
\hline ACE & 66.7 & 53.8 & 0.688 \\
\hline $\mathrm{BCC}$ & 25.0 & 7.7 & 0.322 \\
\hline Metformin & 100.0 & 100.0 & - \\
\hline Insulin & 8.3 & 15.4 & 0.595 \\
\hline
\end{tabular}

$\mathrm{p}$-value for average unpaired t-test; for distribution of relative frequency (\%) p-value for Fisher's Exact test. $\mathrm{BCC}=$ calcium channel blockers; $\mathrm{WC}=$ Waist circumference; $\mathrm{ACE}=$ inhibitors angiotensin converting enzyme; $\mathrm{BMI}=$ body mass index. 
Table II - Mean and standard deviation (SD) of cardiovascular risk factors and heart rate variability indexes for the control and intervention groups at the pre- and post-intervention moments.

\begin{tabular}{lcccccccc} 
& & Pre & Post & Pre & Post & Time & Group & $\begin{array}{c}\text { Interac- } \\
\text { tion }\end{array}$ \\
Variables & Mean \pm SD & Mean \pm SD & Mean \pm SD & Mean \pm SD & p-value & p-value & p-value & $\eta 2$ \\
\hline GL(mg/dL) & $158.6 \pm 39$ & $182.5 \pm 44 \dagger$ & $135.5 \pm 32$ & $112.0 \pm 15 \dagger$ & 0.973 & $0.002^{* *}$ & $0.0001^{*}$ & 0.566 \\
BMI $(\mathrm{kg} / \mathrm{m})$ & $29.9 \pm 7.9$ & $30.1 \pm 8.0$ & $31.0 \pm 6.1$ & $30.4 \pm 3.9 \dagger$ & $0.025^{* * *}$ & 0.784 & $0.0001^{*}$ & 0.439 \\
WC(cm) & $88.0 \pm 29$ & $89.7 \pm 30 \dagger$ & $99.6 \pm 9.1$ & $96.4 \pm 8.1 \dagger$ & 0.071 & 0.303 & $0.0001^{*}$ & 0.621 \\
SBP(mmHg) & $121.5 \pm 13$ & $123.5 \pm 12$ & $128.6 \pm 22$ & $130.8 \pm 17$ & 0.494 & 0.255 & 0.968 & 0.001 \\
DBP(mmHg) & $77.0 \pm 14$ & $73.3 \pm 8.9$ & $80.4 \pm 8.6$ & $75.3 \pm 7.6$ & 0.087 & 0.407 & 0.766 & 0.004 \\
HR(bpm) & $71.9 \pm 10.7$ & $71.8 \pm 10.2$ & $67.0 \pm 11.1$ & $68.6 \pm 11.9$ & 0.510 & 0.362 & 0.449 & 0.025 \\
RMSSD(ms) & $15.7 \pm 11.2$ & $13.9 \pm 9.0$ & $18.0 \pm 8.5$ & $20.2 \pm 10.9$ & 0.897 & 0.25 & 0.254 & 0.056 \\
TINN(ms) & $92.0 \pm 50.1$ & $62.5 \pm 35.4 \dagger$ & $86.1 \pm 55.2$ & $90.3 \pm 52.2$ & 0.113 & 0.55 & $0.039 *$ & 0.173 \\
LF(ms $\left.{ }^{2}\right)$ & $111 \pm 125$ & $80.9 \pm 69$ & $289 \pm 351$ & $272 \pm 225$ & 0,565 & 0.031 & 0.876 & 0.001 \\
LF/HF(ratio) & $1.79 \pm 1.3$ & $2.73 \pm 2.8$ & $2.96 \pm 3.2$ & $2.74 \pm 2.8$ & 0.495 & 0.541 & 0.271 & 0.052 \\
SD1 (ms) & $11.1 \pm 8.0$ & $9.9 \pm 6.4$ & $12.8 \pm 6.0$ & $14.3 \pm 7.7$ & 0.905 & 0.251 & 0.26 & 0.055 \\
SD2(ms) & $30.3 \pm 13.8$ & $24.9 \pm 12.8$ & $39.1 \pm 24.8$ & $39.3 \pm 17.9$ & 0.409 & 0.093 & 0.378 & 0.034 \\
\hline
\end{tabular}

${ }^{*} \mathrm{p} \leq 0,05$ significant effect on interaction time vs. grupo; ${ }^{*}$ significant effect $\mathrm{p}=0.05$ for differences between groups; ${ }^{* * *} \mathrm{p} \leq 0,05$ significant effect of time. $\dagger \mathrm{p}=0.05$ significant differences within the group compared to pre-intervention time by the Post-Hoc test Bonferroni. $\eta 2$ eta squared (effect size); $\mathrm{WC}=$ Waist circumference; $\mathrm{TC}=$ total cholesterol; $\mathrm{HR}=$ heart rate; $\mathrm{GL}=$ fasting glucose; $\mathrm{BMI}=$ body mass index; $\mathrm{DBP}=$ diastolic blood pressure; $\mathrm{SBP}=$ systolic blood pressure; $\mathrm{TG}=$ triglycerides.

There was a significant interaction between group and intervention time for TINN values (ms), indicating improved overall heart rate variability in EG, and reduction in CG. Although not significant from the statistical point of view, there was an increase in the values of RMSSD and SD1 in the EG, and reduction in the CG (Table II). Although no significant reduction in the EG presented LF/HF ratio, inversely to the behavior observed in the control group. However, after controlling for DBP and dyslipidemia it was a significant effect of the intervention with aquatic exercise on values LF/HF by regression analysis (Table III). The baseline values showed a significant effect, but discrete, on the variations of values TINN and SD2. The increase in WC values had a significant effect on the reduction of TINN values. Although the increase of SBP has shown significant effect on the increase of RMSSD values and SD1, as well as the increase in BPD values showed significant effects on the reduction of the LF/ $\mathrm{HF}$, these were discrete and did not demonstrate relevant clinical significance (table III). 
Table III - Analysis of the effect of covariates and the group of the Delta change $(\Delta)$ of the linear rates of heart rate variability.

\begin{tabular}{|c|c|c|c|c|c|c|c|}
\hline \multirow{3}{*}{$\begin{array}{l}\text { Variable } \\
\text { Dependent }\end{array}$} & \multirow{3}{*}{$\begin{array}{c}\text { Variables } \\
\text { Independent }\end{array}$} & \multicolumn{4}{|c|}{ Regression Coefficient } & \multirow{2}{*}{\multicolumn{2}{|c|}{ Model }} \\
\hline & & \multicolumn{3}{|c|}{ CI $95 \%$} & \multirow[b]{2}{*}{ p-value } & & \\
\hline & & B & Inf & Sup & & R2 & p-value \\
\hline \multirow{2}{*}{$\Delta$ RMSSD (ms) } & Constant & -0.3 & -3.4 & 2.9 & 0.86 & \multirow[b]{2}{*}{0.226} & \multirow[b]{2}{*}{$0.016^{*}$} \\
\hline & $\begin{array}{c}\Delta \mathrm{SBP} \\
(\mathrm{mmHg})\end{array}$ & 0.3 & 0.1 & 0.5 & $0.016^{*}$ & & \\
\hline \multirow[t]{3}{*}{$\Delta$ TINN (ms) } & Constant & 13.2 & -13.5 & 39.8 & 0.317 & \multirow{3}{*}{0.506} & \multirow{3}{*}{$0.0001 * *$} \\
\hline & $\Delta \mathrm{WC}(\mathrm{cm})$ & -6.5 & -10.7 & -2.3 & $0.004^{*}$ & & \\
\hline & $\begin{array}{l}\text { Pre TINN } \\
\quad(\mathrm{ms})\end{array}$ & -0.3 & -0.6 & -0.1 & $0,010^{*}$ & & \\
\hline \multirow[t]{3}{*}{$\Delta \mathrm{LF}\left(\mathrm{ms}^{2}\right)$} & Constant & 72.1 & 8.6 & 135.7 & $0.027^{*}$ & \multirow{3}{*}{0.653} & \multirow{3}{*}{$0,007^{*}$} \\
\hline & LF (ms) pre & -0.6 & -0.8 & -0.4 & $0.0001 *$ & & \\
\hline & $\Delta \mathrm{DC}(\mathrm{cm})$ & -23.9 & -40.8 & -7 & $0,007^{*}$ & & \\
\hline \multirow[t]{4}{*}{$\Delta \mathrm{LF} / \mathrm{HF}$} & Constant & 1.3 & 0.01 & 2.6 & 0.055 & \multirow{4}{*}{0.609} & \multirow{4}{*}{$0.0001^{* *}$} \\
\hline & $\begin{array}{c}\Delta \mathrm{DBP} \\
(\mathrm{mmHg})\end{array}$ & -0.1 & -0.2 & -0.1 & $0.0003^{*}$ & & \\
\hline & Dyslipidemia & -1.7 & -3.1 & -0.2 & $0.029^{*}$ & & \\
\hline & Group & -1.4 & -2.9 & -0.01 & $0.050^{*}$ & & \\
\hline \multirow[t]{2}{*}{$\Delta \mathrm{SD1}(\mathrm{ms})$} & Constant & -0.2 & -2.4 & 2 & 0.848 & \multirow[b]{2}{*}{0.229} & \multirow[b]{2}{*}{$0.015^{*}$} \\
\hline & $\begin{array}{c}\Delta \mathrm{SBP} \\
(\mathrm{mmHg})\end{array}$ & 0.2 & 0 & 0.4 & $0.015^{*}$ & & \\
\hline \multirow[t]{2}{*}{$\Delta \mathrm{SD} 2(\mathrm{~ms})$} & Constant & 12.6 & 2.01 & 23.17 & 0.022 & \multirow{2}{*}{0.334} & \multirow{2}{*}{$0.002^{* *}$} \\
\hline & SD2 (ms) pre & -0.43 & -0.69 & -0.17 & $0.002 *$ & & \\
\hline
\end{tabular}

$\mathrm{B}=$ regression coefficient $; \mathrm{CI}=$ confidence interval for the regression coefficient; $\mathrm{Inf}=$ lower limit; Sup = upper limit; * $\mathrm{P} \leq 0,05$ significant effect of the independent variable regression coefficient; ${ }^{* *} \mathrm{p} \leq 0,05$ significant effect of the delta model to predict changes in the dependent variable; $R 2=$ proportion of variation of the dependent variable explained by the independent variables. WC = Waist circumference; Dyslipidemia $(0=$ absent, $1=$ present $)$; Group $(0=$ control/ intervention = 1); DBP = diastolic blood pressure; SBP = systolic blood pressure.

\section{Discussion}

As for the characteristics of the sample was observed high prevalence of cardiovascular risk factors and osteoarthritis, indicating the effects of both the aging process associated with post-menopausal condition, as the deleterious effects of hyperglycemic state related to T2DM [19]. The high prevalence of comorbid conditions in the sample also suggests that damage to ASN should already be present, primarily due to the high prevalence of high blood pressure (hypertension) and time of diagnosis of T2DM in the sample [20]. Although the use of reference values for interpretation of HRV indices are still of controversial [21], it can be observed in the present study that the sample presented in the baseline reduced values of linear indexes representing the global variability (SD2) and parasympathetic (RMSSD and SD1) [22,23], suggesting the presence of autonomic dysfunction in the studied sample. 
Regarding the effect of intervention with aquatic exercise, we observed significant reductions in cardiovascular risk factors, but there was no significant effect of aquatic exercise with intervention on blood pressure and resting heart rate. Regarding the HRV index, it was a significant interaction effect only on TINN values (ms) with a slight increase in EG, but especially significant reduction in CG. Regression analysis indicated a possible effect of aquatic exercise in reducing the ratio values LF / HF, but this effect was dependent on the presence of dyslipidemia and reductions in DBP.

Despite the increase in most linear indices of HRV (RMSSD, SD1 and SD2) in EG, these were not confirmed by statistical analysis. This is because the effect of exercise on cardiac autonomic modulation appears to be dependent overload exercise and the intervention time [24]. The low adherence (65\%) of attendance at training sessions may have influenced the effect of aquatic exercise on autonomic modulation. However when considering the high prevalence of comorbidities in the population of post-menopausal women with type 2 diabetes, poor adherence to exercise programs reflects a clinical reality, since these patients have to be away frequently to appear in medical visits, as well as to assist in family care [25].

Among the studies that showed significant effect of 12 weeks of physical exercise of moderate intensity to vigorous on cardiac autonomic modulation, the use of three weekly sessions proves to be an important aspect $[12,26,27]$, which indicates that a higher weekly frequency can contribute positively to the improvement of autonomic modulation. The effect of the increase in weekly frequency on the extent of improvement in cardiac autonomic modulation can be observed [28], indicating the importance of this component of the exercise load on the observable adaptations in cardiac autonomic modulation. But in none of these studies it was observed using aquatic exercise.

Thus, two weekly sessions may not be sufficient to observe a significant effect on cardiac autonomic modulation at 12 weeks of intervention with exercise of moderate to vigorous, particularly when there is a low adhesion to training sessions, as found in this study. On the other hand, in the case of a long-term aquatic exercise intervention $[13,14]$ or on land $[11,29]$, however, two weekly sessions of moderate to vigorous intensity, significant effects were observed in the improvement of autonomic cardiac modulation. Thus the effect of exercise of moderate to vigorous on autonomic modulation shown dependent on the relationship between the intervention time and the weekly frequency of exercise sessions.

Another factor that can influence the effect of intervention with aquatic exercise in the adaptation of cardiac autonomic modulation response is the values observed at baseline, which are also related to the health condition of the patient. It was observed by regression analysis that the reduced values at baseline were related to higher variations of TINN values and SD2. Relationship can also be observed in other intervention studies with exercise [30-32]. The effects of highest amplitude on cardiac autonomic modulation occurred in those subjects with reduced values at baseline and were associated with the presence of pathological conditions.

The regression analysis also indicated that factors such as dyslipidemia and variations in WC, SBP and DBP can also significantly influence HRV adjustments. Dyslipidemia significant effect on reducing the LF values (nu) and LF/ HF ratio. Although the presence of dyslipidemia and low HRV are related to a 
higher cardiovascular risk, the relationship between serum lipids and HRV is still little studied in patients with diabetes and cardiovascular disease [33]. $\mathrm{Ne}-$ vertheless, the presence of dyslipidemia is an unfavorable condition to health, and therefore may be related to reduce HRV, which favors its increase in response to intervention with physical exercise.

Central obesity has been linked to a worse cardiac autonomic modulation and reduced HRV [10]. It was observed that by regression analysis reductions in WC contributed significantly increase the overall variability represented by TINN index (ms). Regarding the effect of reducing the WC on the reduction of the LF values $\left(\mathrm{ms}^{2}\right)$, this was observed only in patients with LF values $\left(\mathrm{ms}^{2}\right)$ higher at baseline. On the other hand, for patients with LF values $\left(\mathrm{ms}^{2}\right)$ reduced the baseline was observed that reducing the WC contributed to the increase of $\mathrm{LF}$ values $\left(\mathrm{ms}^{2}\right)$. However, in those patients with LF values $\left(\mathrm{ms}^{2}\right)$ reduced at baseline, the increases in their values should be interpreted as a positive adaptation [30], because very low LF values $\left(\mathrm{ms}^{2}\right)$ are related to autonomic dysfunction [31,34].

Although significant effect of varying the PAS on RMSSD values and SD1 by regression analysis, this effect was small, a large variation is required SBP to produce a considerable effect on these indices of HRV. The reduction PAD significant effect in reducing the LF / HF ratio, but this effect was more evident in patients with dyslipidemia. Thus, those volunteers with dyslipidemia who underwent aquatic exercise and decreased DBP showed the highest reductions in the ratio values LF / HF. This effect may be related to improved baroreflex sensitivity, which in turn is related to improvements for the HRV $[35,36]$.

Although 12-week aquatic exercise have produced a slight effect on cardiac autonomic modulation of postmenopausal women with type 2 diabetes, decreases in the body composition and FGB parameters indicate a protective effect of aquatic exercise in the progression of autonomic dysfunction [4,32], because, from a clinical point of view, the maintenance of cardiac autonomic balance is directly related to the improvement of glycemic control and improvement of the health condition of patients with T2DM [37].

A limitation of the study is related to the method used to control the intensity of physical exercise. Although the use of the Borg effort perception scale is widely accepted, this isolated method may not be accurate. An interesting alternative for controlling exercise intensity would be the use of heart rate monitoring together with the effort perception scale. The use of heart rate and the stress perception scale in a combined way is important, because, in the elderly population with diabetes, both autonomic dysfunction and the use of beta-blocking medication can alter the heart rate response.

Regarding the type of exercise, few studies have examined the relationship between aquatic exercise and cardiac autonomic modulation $[13,14]$, and none of them are analyzed in relation population of postmenopausal women with T2DM. Thus, this study back important contributions to research on the relationship between water exercise and cardiac autonomic modulation of patients with T2DM postmenopausal condition. Furthermore, there is evidence that exercise in water can promote greater adherence to exercise programs, besides allowing the achievement of exercise vigorously intensity for a longer time, even in patients with symptoms of pain, osteoarticular diseases and reduced capacity functional $[38,39]$. 


\section{Conclusion}

Although the effect of aquatic exercise program on rising TINN values (ms) has been slight and the effect in reducing the LF/HF ratio was dependent on the reduction of DBP and the presence of dyslipidemia, factors such as low compliance $(65 \%)$ of EG and the low time and number of weekly sessions seem to explain in part the results. Although the results do not allow confirmation of a large aquatic exercise effect in the improvement of cardiac autonomic modulation, the significant reduction of cardiovascular risk factors indicates that it is the mode of exercise that may at least represent a protective factor for progression of cardiac autonomic dysfunction in postmenopausal women with type 2 diabetes.

\section{Declaration of interest}

The authors declare no conflict of interest.

\section{References}

1. Barbosa JHP, Oliveira SL, Seara LT. O papel dos produtos finais da glicação avançada (AGEs) no desencadeamento das complicações vasculares do diabetes. Arq Bras Endocrinol Metab 2008;52(6):940-50. https://doi.org/10.1590/S0004-27302008000600005

2. Hautamäki H, Mikkola TS, Sovijärvi ARA, Piirilä P, Haapalahti P. Menopausal hot flushes do not associate with changes in heart rate variability in controlled testing: A randomized trial on hormone therapy. Acta Obstet Gynecol Scand 2013;92(8):902-8. https://doi.org/10.1111/ aogs.12164

3. Vinik AI, Maser RE, Mitchell BD, Freeman R. Diabetic autonomic neuropathy. Diabetes Care [Internet] 2003;26(5):1553-79. https://doi.org/10.2337/diacare.26.5.1553

4. Fleischer J, Yderstraede K, Gulichsen E, Jakobsen PE, Lervang HH, Eldrup E, et al. Cardiovascular autonomic neuropathy is associated with macrovascular risk factors in type 2 diabetes: New technology used for routine large-scale screening adds new insight. J Diabetes Sci Technol 2014;8(4):874-80. https://doi.org/10.1177/1932296814528616

5. Lopes PFF, Oliveira MIB, André SMS, Nascimento DLA, Silva CSS, Rebouças GM, et al. Aplicabilidade clínica da variabilidade da frequência cardíaca. Rev Neurociencias 2013;21(4):600-3. https://doi.org/10.4181/RNC.2013.21.870.4p

6. Narayanaswamy N, Moodithaya S, Halahalli H, Mirajkar AM. Assessment of risk factor for cardiovascular disease using heart rate variability in postmenopausal women: a comparative study between urban and rural Indian women. ISRN Cardiol [Internet]. 2013;2013:1-6. https:// doi.org/10.1155/2013/858921

7. Stranieri A, Abawajy J, Kelarev A, Huda S, Chowdhury M, Jelinek HF. An approach for Ewing test selection to support the clinical assessment of cardiac autonomic neuropathy. Artif Intell Med 2013;58(3):185-93. http://doi.org/10.1016/j.artmed.2013.04.007

8. Colberg SR, Sigal RJ, Yardley JE, Riddell MC, Dunstan DW, Dempsey PC et al. Physical activity/exercise and diabetes: A position statement of the American Diabetes Association. Diabetes Care 2016;39(11):2065-79. https://doi.org/10.2337/dc16-1728

9. American Diabetes Association (ADA). Standards of medical care in diabetes. Diabetes Care 2019;42(s1).

10. Voulgari C, Pagoni S, Vinik A, Poirier P. Exercise improves cardiac autonomic function in obesity and diabetes. Metabolism 2013;62(5):609-21. http://doi.org/10.1016/j.metabol.2012.09.005

11. Sacre JW, Jellis CL, Jenkins C, Haluska BA, Baumert M, Coombes JS et al. A six-month exercise intervention in subclinical diabetic heart disease: Effects on exercise capacity, autonomic and myocardial function. Metabolism 2014;63(9):1104-14. https://doi.org/10.1016/j.metabol.2014.05.007

12. Kang S-J, Ko K-J, Baek U-H. Effects of 12 weeks combined aerobic and resistance exercise on heart rate variability in type 2 diabetes mellitus patients. J Phys Ther Sci 2016;28(7):2088-93. Available from: https://www.jstage.jst.go.jp/article/jpts/28/7/28_jpts-2016-178/_article

13. Zamunér AR, Andrade CP, Forti M, Marchi A, Milan J, Avila MA et al. Effects of a hydrotherapy programme on symbolic and complexity dynamics of heart rate variability and aerobic capacity in fibromyalgia patients. Clin Exp Rheumatol 2015;33(14):S73-81.

14. Albinet CT, Abou-Dest A, André N, Audiffren M. Executive functions improvement following 
a 5-month aquaerobics program in older adults: Role of cardiac vagal control in inhibition performance. Biol Psychol 2016;115:69-77. https://doi.org/10.1016/j.biopsycho.2016.01.010

15. ABESO. Diretrizes Brasileiras de obesidade. 4th ed. https://abeso.org.br/wp-content/uploads/2019/12/Diretrizes-Download-Diretrizes-Brasileiras-de-Obesidade-2016.pdf

16. Laborde S, Mosley E, Thayer JF. Heart rate variability and cardiac vagal tone in psychophysiological research - Recommendations for experiment planning, data analysis, and data reporting. Front Psychol 2017;8(2):1-18. https://doi.org/10.3389/fpsyg.2017.00213.

17. Olkoski MM, Matheus SC, Moraes EC, Tusset D. Metodologia para o planejamento de aulas de hidroginastica. Motricidade 2013;9(3):36-43. https://doi.org/10.6063/motricidade.9(3).688

18. Borg G. Psychophysical basis of perceived exhertion. Med Sci Sports Exerc 1982;14(5):377-81. 19. Filippatos T, Tsimihodimos V, Pappa E, Elisaf M. Pathophysiology of diabetic dyslipidaemia. Curr Vasc Pharmacol 2017;15(6):1-10. https://doi.org/10.5551/jat.RV17023

20. Bianchi L, Volpato S. Muscle dysfunction in type 2 diabetes: a major threat to patient's mobility and independence. Acta Diabetol 2016;53(6):879-89. https://doi.org/10.1007/s00592-0160880-y

21. Bauer A, Camm AJ, Cerutti S, Guzik P, Huikuri H, Lombardi F et al. Reference values of heart rate variability. Heart Rhythm 2017;14(2):302-3. https://doi.org/10.1016/j.hrthm.2016.12.015

22. Lee $\mathrm{CH}$, Lee JH, Son JW, Kim U, Park JS, Lee J et al. Normative values of short-term heart rate variability parameters in koreans and their clinical value for the prediction of mortality. Heart Lung Circ 2018;27(5):576-87. https://doi.org/10.1016/j.hlc.2017.04.009

23. Sammito S, Böckelmann I. New reference values of heart rate variability during ordinary daily activity. Heart Rhythm 2017;14(2):304-7. https://doi.org/10.1016/j.hrthm.2016.12.016

24. Michael S, Graham KS, Davis GM. Cardiac autonomic responses during exercise and post-exercise recovery using heart rate variability and systolic time intervals-a review. Front Physiol 2017;8:1-19.

25. Chagas EFB, Bonfim MR, Turi BC, Brondino NCM, Monteiro HL. Effect of moderate-intensity exercise on inflammatory markers among postmenopausal women. J Phys Act Heal 2017;14(6):479-85. https://doi.org/10.1123/jpah.2016-0319

26. Sales ARK, Silva BM, Neves FJ, Rocha NG, Medeiros RF, Castro RRT et al. Diet and exercise training reduce blood pressure and improve autonomic modulation in women with prehypertension. Eur J Appl Physiol 2012;112(9):3369-78. https://doi.org/10.1007/s00421-012-2315-y.

27. Duarte A, Soares PP, Pescatello L, Farinatti P. Aerobic training improves vagal reactivation regardless of resting vagal control. Med Sci Sports Exerc 2015;47(6):1159-67. https://doi. org/10.1249/MSS.0000000000000532

28. Simmonds MJ, Minahan CL, Serre KR, Gass GC, Marshall-Gradisnik SM, Haseler LJ, et al. Preliminary findings in the heart rate variability and haemorheology response to varied frequency and duration of walking in women 65-74 yr with type 2 diabetes. Clin Hemorheol Microcirc 2012;51(2):87-99. https://doi.org/10.3233/CH-2011-1514.

29. Zoppini G, Cacciatori V, Gemma ML, Moghetti P, Targher G, Zamboni C et al. Effect of moderate aerobic exercise on sympatho-vagal balance in Type 2 diabetic patients. Diabet Med 2007;24(4):370-6. https://doi.org/10.1111/j.1464-5491.2007.02076.X

30. Figueroa A, Baynard T, Fernhall B, Carhart R, Kanaley JA. Endurance training improves post-exercise cardiac autonomic modulation in obese women with and without type 2 diabetes. Eur J Appl Physiol 2007;100(4):437-44. https://doi.org/10.1007/s00421-007-0446-3

31. Pagkalos M, Koutlianos N, Kouidi E, Pagkalos E, Mandroukas K, Deligiannis A. Heart rate variability modifications following exercise training in type 2 diabetic patients with definite cardiac autonomic neuropathy. Br J Sports Med. 2008;42(1):47-54. https://doi.org/10.1136/ bjsm.2007.035303

32. Earnest CP, Poirier P, Carnethon MR, Blair SN, Church TS. Autonomic function and change in insulin for exercising postmenopausal women. Maturitas 2010;65(3):284-91.

33. Badea AR, Nedelcu L, Valeanu M, Zdrenghea D. The relationship between serum lipid fractions and heart rate variability in diabetic patients with statin therapy. Clujul Med 2014;87(3):152. http://www.clujulmedical.umfcluj.ro/index.php/cjmed/article/view/313

34. Dimitropoulos G. Cardiac autonomic neuropathy in patients with diabetes mellitus. World J Diabetes 2014;5(1):17. training improves baroreflex sensitivity in type 2 diabetes. Diabetes 2003;52(7):1837-42. https://doi.org/10.2337/diabetes.52.7.1837

35. Bernardi L, Bianchi L. Integrated cardio-respiratory control: insight in diabetes. Curr Diab Rep 2016;16(11). https://doi.org/10.1007/s11892-016-0804-9

36. Jones SMW, Guthrie KA, LaCroix AZ, Sternfeld B, Landis CA, Reed SD et al. Is heart rate variability associated with frequency and intensity of vasomotor symptoms among healthy perimenopausal and postmenopausal women? Clin Auton Res 2016;26(1):7-13. https://doi. org/10.1007/s10286-015-0322-x

37. Loimaala A, Huikuri HV, Kööbi T, Rinne M, Nenonen A, Vuori I. Exercise training improves baroreflex sensitivity in type 2 diabetes. Diabetes 2003;52:1837-42. 
38. Igarashi Y, Nogami Y. The effect of regular aquatic exercise on blood pressure: A meta-analysis of randomized controlled trials. Eur J Prev Cardiol 2018;25(2):190-9. https://doi. org $/ 10.1177 / 2047487317731164$

39. Rees JL, Johnson ST, Boulé NG. Aquatic exercise for adults with type 2 diabetes: a meta-analysis. Acta Diabetol 2017;54(10):895-904. https://doi.org/10.1007/s00592-017-1023-9 